\title{
9p21 Locus Polymorphisms: Risk and Severity Factors of Coronary Artery Disease in Venezuelan Patients
}

\author{
Susana Blanco Sobrino, ${ }^{1}$ Eva Salazar Alcalá, ${ }^{2}$ Asdrúbal Alfonzo Reyes, ${ }^{1}$ Jesus Flores-Soler, ${ }^{\circledR}$ Romina Leras \\ Mirabal, ${ }^{1}$ Yettana Luti, ${ }^{1}$ Ingrid Márquez, ${ }^{3}$ Mercedes Teresita Fernandez Mestre ${ }^{2}$ \\ Hospital Central del Instituto Venezolano de los Seguros Sociales "Dr. Miguel Pérez Carreño", Caracas - Venezuela \\ Instituto Venezolano de Investigaciones Científicas, ${ }^{2}$ Miranda - Venezuela \\ Hospital General del Este "Dr. Domingo Luciani",3 Miranda - Venezuela
}

\section{Abstract}

Background: The 9p21 region is the most relevant locus associated with coronary heart disease in different populations. However, there are no studies that prove that this region is a risk factor in the Venezuelan population.

Objectives: To analyze whether or not the $9 p 21$ rs1333049 polymorphism is a risk factor for acute myocardial infarction (AMI) in Venezuelan patients, as well as to investigate its correlation with cardiovascular risk factors (CVRF), age of occurrence, type and severity of infarction, and the correlation of the rs10757274 polymorphism with severity of coronary artery disease.

Methods: This was an association study, including 487 unrelated Venezuelan individuals, grouped in 354 patients with AMI and 133 controls. The rs1333049 and rs10757274 polymorphisms were determined using the polymerase chain reaction (PCR) technique with sequence-specific primers. The analysis of association was determined using the SNPStats tool. The continuous variable description and the correlations were performed using the SPSS statistical software. Significance was established at $\mathrm{p}<0.05$.

Results: A positive correlation was observed between the rs1333049 polymorphism and the presence of hypertension $(r: 0.145, p: 0.006)$, and between hypertension and heart infarction $(r: 0.318, p:<0.0001)$. A positive correlation was found between the rs10757274 polymorphism and the number of coronary vessels that presented obstructive lesions in patients aged $\leq 55$ years $(r: 0.276, p: 0.0078)$.

Conclusion: The rs1333049 polymorphism at the $9 p 21$ locus is correlated with hypertension in Venezuelan patients, while the rs10757274 polymorphism is associated with the progression of coronary atherosclerosis, suggested by the correlation with the number of coronary vessels that presented significant obstructive lesions.

Keywords: Cardiovascular Diseases/complications; Polymorphism/ genetics; Coronary Artery Disease; Myocardial Infarction; Chromosomes (9p21)/ genetics; Epidemiology; Atherosclerosis.

\section{Introduction}

Cardiovascular diseases (CVDs) represent the leading cause of death worldwide. An estimated 17.9 million people died from CVDs in 2016, representing 31\% of all deaths registered worldwide. ${ }^{1}$ Ischemic heart disease was the first specific cause of mortality in Venezuela in 2015 , causing 31,338 deaths, representing $18 \%$ of the total mortality burden and $59 \%$ of cardiovascular mortality. ${ }^{2}$
Epidemiological studies have shown that, in addition to conventional risk factors, environmental factors and lifestyle increase the susceptibility to developing coronary artery disease (CAD). Apart from these factors, studies carried out in twins and nuclear families show that genetic predisposition plays an important role in the pathogenesis of CAD. Although population studies have described multiple genetic variations contributing to the inheritance of CAD risk, the exact identity of candidate

Mailing Address: Mercedes Fernandez Mestre

Carretera Panamericana, Km 11. Postal Code 1020A, Alto de Pipe, Caracas - Venezuela.

E-mail: mfernandezmestre@gmail.com 
genes and their effect on disease pathogenesis are not well known. ${ }^{3}$ However, epidemiological and family studies, among others, suggest that approximately $50 \%$ of the susceptibility to CAD is due to genetic markers. ${ }^{4}$

Genome-wide association studies (GWAS) have shown that the 9p21 locus is associated with CAD. ${ }^{5-8}$ In conjunction, the Wellcome Trust Case Control Consortium (WTCCC) ${ }^{9}$ and studies carried out in Germany, ${ }^{8}$ Japan, $^{10,11}$ Korea, ${ }^{11,12} \mathrm{China}^{13}{ }^{13}$ Italy, ${ }^{14}$ among others, have considered the $9 p 21$ locus as a risk factor for CAD. This locus has several polymorphisms, but only five of them, rs1333049, rs10757274, rs2383206, rs2383207, and rs10757278, play an important role in the development and prediction of CAD.${ }^{15}$ However, although the $9 p 21$ locus is considered a risk factor for coronary heart disease in Caucasian and Asian populations, it is not a risk factor in AfricanAmerican populations. Although studies of African Americans have been limited, the 9p21 locus appears to be a risk factor in all ethnic groups that migrated out of Africa. In these groups, it appears that the evolutionary time has not elapsed to break and intermix the haplotype that carries the risk polymorphisms. In contrast, in Africans, who have a longer evolutionary history, the $9 p 21$ risk haplotype has been excised into small haplotypes that produce no or a minimal risk of developing coronary heart disease. ${ }^{4}$

Considering that the $9 p 21$ region is the most relevant locus and has been associated with CAD in different populations, two haplotype-tagging single nucleotide polymorphisms (SNPs) were selected. The SNPs: rs1333049 present in whites and rs10757274 present in both races (whites and blacks), considering the importance of an ancestry-specific allele context. ${ }^{16.17}$ The objective of the present study was to analyzed whether the rs1333049 polymorphism in the 9p21 locus represents a risk marker for acute myocardial infarction (AMI) in the Venezuelan mestizo population. Likewise, the possible correlation of an rs1333049 polymorphism with traditional risk factors, age of occurrence, type and severity of AMI, as well as the correlation of the rs10757274 polymorphism in the 9p21 locus, coupled with the severity of CAD, was investigated.

\section{Methods}

\section{Design}

This was an association (case-control) and correlational study.

\section{Study Population}

The study included 487 Venezuelan individuals, unrelated, classified into two groups.

1. Patients $(n=354)$. Individuals with a diagnosis of AMI, determined by clinical, paraclinical, and electrocardiographic findings, who attended the Coronary Care Unit of Hospital Central del Instituto Venezolano de los Seguros Sociales "Dr. Miguel Pérez Carreño", Coronary Care Unit and Special Studies Unit of the Cardiology Service of the Hospital General del Este "Dr. Domingo Luciani".

2. Controls $(n=133)$. Apparently healthy individuals with or without cardiovascular risk factors (CVRF).

In both groups, those individuals with a history of hepatic, autoimmune, neoplastic diseases, or infarction secondary to other causes were excluded. All participating individuals signed a consent approved by the Bioethics Committee of the participating institutions (DIR-0130/09; official letter No. 00211)

\section{Clinical classification of patients with Myocardial infarction (MI)}

Based on the admission electrocardiogram (ECG) and the clinical characteristics of infarcted patients, Myocardial infarction (MI) was classified as:

1. Non-ST-segment elevation (NSTEMI)

2. ST-segment elevation (STEMI).

\section{Types of coronary artery disease}

According to the results of the coronary angiography, the patients were classified into two groups:

1. Obstructive CAD. Patients with significant epicardial coronary artery lesions and coronary stenosis $\geq 50 \%$

2. Non-significant obstructive coronary artery disease (non-CAD). Patients without coronary artery stenosis in any artery related to the infarction. This includes both patients with normal coronary arteries (no stenosis $>30 \%$ ) or mild coronary atheromatosis (stenosis $>30 \%$, but $<50 \%$ ).

\section{Chromosome 9p21 locus genotyping}

To determine the genetic polymorphisms of the $9 p 21$ locus, genomic DNA was extracted from venous white blood cells using the Bunce protocol. ${ }^{18}$ 
The rs1333049 polymorphism in the $9 p 21$ locus was determined using the primers and the protocol described by Ahmed et al., ${ }^{19}$ For this, two reaction mixtures were prepared, one for the amplification of the ancestral or wild allele $[G]$ and the other for the mutated allele [C]. For genotyping, the amplified products, a $280 \mathrm{bp}$ fragment for the specific alleles ( $\mathrm{C}$ and $\mathrm{G}$, respectively) and $500 \mathrm{bp}$ for the internal control, were electrophoretically separated on $2 \%$ agarose gels and stained with ethidium bromide $(0.5 \mu \mathrm{g} / \mathrm{ml})$. The amplified products were viewed through a photo documentation equipment (Chemic Doc, BIORAD).

The rs10757274 polymorphism in the $9 p 21$ locus was determined using the primers and the protocol described by Nawaz et al., ${ }^{20}$ For this, two reaction mixtures were prepared, one for the amplification of the ancestral or wild allele [A] and the other for the mutated allele [G]. For genotyping, the amplified products, a $250 \mathrm{bp}$ fragment for the specific alleles (A and G, respectively), and 419 bp for the internal control, were electrophoretically separated on $2 \%$ agarose gels and stained with ethidium bromide $(0.5 \mu \mathrm{g} / \mathrm{ml})$. The amplified products were viewed through a photo documentation equipment (Chemic Doc, BIORAD).

\section{Presence and severity of CAD}

To determine the presence of $\mathrm{CAD}$, in the Coronary Care Unit of Hospital Central del Instituto Venezolano de los Seguros Sociales "Dr. Miguel Pérez Carreño", diagnostic coronary angiography was performed in 76 patients, using a femoral or radial approach. The technique is determined by the vascular accessibility of the patient and the preference of the operator. All angiographies were filmed at 15 frames / s and Cine, stored at the time of acquisition in DICOM format. For the evaluation of the severity of $\mathrm{CAD}$, the definition established by the American College of Cardiology was used, where the severity of the injury, according to the visual obstruction of the lumen, was classified as Mild: $<50 \%$, Moderate: $50-69 \%$, and Severe: $\geq 70 \%$. Considering significant obstructive CAD when, obstruction was observed of one or more epicardial arteries with at least $70 \%$ stenosis. Significant lesions were classified into three types of lesions: A, B, and C. This definition was used for the left (anterior descending artery, circumflex artery) and right (right coronary artery) circuit, with the exception of the left main trunk, for which the disease is present when there is a compromise $\geq 50 \%$ of the vessel diameter. ${ }^{21}$

\section{Statistical analysis}

The sample size to achieve $80 \%$ statistical power was calculated according to the genetic models and the heterozygous odds ratios (OR) using a single SNP marker in a case-control study under the assumptions of $5 \%$ disease prevalence, $5 \%$ minor allele frequency (MAF), complete linkage disequilibrium (LD), 1:1 caseto-control ratio, and $5 \%$ type I error rate $(\alpha){ }^{22}$ However, in the present study, more data was obtained from affected individuals than from healthy individuals. For this reason, the analysis of association with AMI was adjusted for the selected covariates (cardiovascular risk factors). The Hardy Weinberg equilibrium (HW) and the inheritance models were determined using the SNPStats tool. ${ }^{23}$ With this tool, the analysis was also performed to determine the possible susceptibility conferred by the $9 p 21$ polymorphism to develop into a myocardial infarction. To analyze for binary responses, the logistic regression analysis is summarized with genotype frequencies, proportions, OR, and 95\% confidence intervals (CI). The statistical significance of genotype frequency differences between patients and controls was estimated by the X2 Mantel-Haenszel test. Probability (p) values $<0.05$ were considered significant. P-values were adjusted with Bonferroni correction. The continuous quantitative variables were described as mean \pm standard deviation (SD), and data normality was tested using the Shapiro-Wilk test. To determine the difference between the means, an unpaired t-test was applied at a 95\% CI. The correlations between the variability of the studied polymorphisms, traditional CVRF, occurrence, type and severity of AMI, and the severity of CAD were determined through Pearson's correlation coefficient, using the statistical package SPSS Statistics, version $20 .^{24}$

\section{Results}

Demographic, anthropometric, and clinical characteristics of patients with AMI and apparently healthy individuals (controls) are shown in Table 1. When establishing comparisons of the CVRF between both groups, a significantly increased frequency of male individuals was observed (OR: 3; 95\% CI: 2.032-4.63; p $<0.00001$ ), cases of hypertension (OR: 4.5 ; $95 \%$ CI: 2.908 7.076; p: <0.00001), smoking (OR: 4.9; 95\% CI: 2.789-8.905; p: <0.00001), obesity (OR: 2.5; 95\% CI: 1.616-3.927; p: $<0.000011$ ), and sedentary lifestyle (OR: 1.9; 95\% CI: 1.236 3.059; p: 0.001) in the group of patients versus apparently healthy individuals. Likewise, the differences in mean 


\begin{tabular}{|c|c|c|c|}
\hline Characteristics & AMI Patients $(n=354)$ & Characteristics & Controls $(n=133)$ \\
\hline Sex & & Sex & \\
\hline Female & $29.7(249)$ & Female & $56.4(75)$ \\
\hline Male & $70.3(105)$ & Male & $43.6(58)$ \\
\hline Age Range (years) & $24-90$ & Age Range (years) & $30-83$ \\
\hline Age (years) & $57.46 \pm 13.22$ & Age (years) & $51.79 \pm 10.82$ \\
\hline Weight (kg) & $76.56 \pm 15.26$ & Weight (kg) & $76,11 \pm 15,85$ \\
\hline Size (m) & $1,64 \pm 008$ & Size (m) & $1,63 \pm 0,09$ \\
\hline BMI $(\mathrm{kg} / \mathrm{m} 2)$ & $28,38 \pm 4,51$ & BMI (kg/m2) & $28,69 \pm 4,92$ \\
\hline Waist circumference $(\mathrm{cm})$ & $98,41 \pm 10,83$ & Waist circumference $(\mathrm{cm})$ & $94,40 \pm 11,62$ \\
\hline CVRF & & CVRF & \\
\hline HT $(n=354)$ & $66.4(235)$ & HT (n=122) & $30.3(37)$ \\
\hline $\mathrm{DM}(\mathrm{n}=345)$ & $23.5(81)$ & $\mathrm{DM}(\mathrm{n}=102)$ & $19.6(20)$ \\
\hline Smoking ( $\mathrm{n}=352$ ) & $40.9(144)$ & Smoking $(\mathrm{n}=123)$ & $12.2(15)$ \\
\hline Obesity (n=337) & $51.3(173)$ & Obesity (n=122) & $29.5(36)$ \\
\hline Dyslipidemia ( $\mathrm{n}=339$ ) & $37.4(127)$ & Dyslipidemia $(\mathrm{n}=120)$ & $27.5(33)$ \\
\hline Sedentary lifestyle $(\mathrm{n}=351)$ & $42.4(149)$ & Sedentary lifestyle $(n=120)$ & $27.5(33)$ \\
\hline \multicolumn{4}{|l|}{ Clinical presentation } \\
\hline NSTEMI & $42.8(151)$ & & \\
\hline STEMI & $57.2(202)$ & & \\
\hline
\end{tabular}

Frequencies are expressed in percentages. The values shown in parentheses represent the number of individuals. Values of continuous variables are expressed as mean \pm Standard deviation. AMI: Acute myocardial infarction, BMI: body mass index (kg / 2 2); CVRF: Cardiovascular risk factors, HT: Hypertension, DM: Diabetes mellitus, NSTEMI: Myocardial infarction without ST segment elevation, STEMI: Myocardial infarction with ST segment elevation.

values of age (p: 0.00001) and waist circumference (p: $0.0005)$ were significantly higher in patients. Regarding the clinical presentation of the infarction, more than $50 \%$ of patients were clinically classified as patients with STEMI.

Using the SNPstats program, the existence of the H-W equilibrium for the genotypic distribution of rs1333049 polymorphism in the $9 p 21$ locus was confirmed in apparently healthy individuals. Jointly, the inheritance model of the homozygous mutated genotype (CC) of the rs1333049 variant was determined, establishing the dominant model as the most adjusted, presenting the lowest probability value. This pattern of inheritance indicates that a single copy of the $\mathrm{C}$ allele is enough to modify risk, and being a carrier of two copies modifies it in equal magnitude. The carriers of the GC and CC genotypes have the same risk.

When establishing the comparison of genotypic and allele frequencies of the rs1333049 variant, among patients with AMI and apparently healthy individuals, and among infarcted patients with STEMI and NSTEMI, both adjusted for CVRF and considering the dominant inheritance model, no significant differences were observed (Table 2).

The correlation analysis showed a positive correlation between the rs1333049 polymorphism and the presence of hypertension (r: 0.145, p: 0.006), and between hypertension and acute myocardial infarction (r: 0.318, $\mathrm{p}:<0.0001)$. Based on these correlations, the comparison of genotype frequencies between AMI patients with 
Table 2 - Association of rs1333049 polymorphism in the $9 p 21$ locus with the development of AMI and type of myocardial infarction

\begin{tabular}{|c|c|c|c|c|}
\hline $\begin{array}{l}\text { rs1333049 } \\
\text { Genotypes }\end{array}$ & $\begin{array}{l}\text { AMI patients } \\
\qquad(n=314)\end{array}$ & $\begin{array}{l}\text { Controls } \\
(n=94)\end{array}$ & $\begin{array}{c}\text { OR } \\
95 \% C I\end{array}$ & $P$ \\
\hline GG & $31.9(100)$ & $36.2(34)$ & $0.8(0.508-1.336)$ & 0.21 \\
\hline GC & $50.6(159)$ & $48.9(46)$ & $1.0(0.675-1.697)$ & 0.38 \\
\hline $\mathrm{CC}$ & $17.5(55)$ & $14.9(14)$ & $1.2(0.641-2.296)$ & 0.27 \\
\hline \multicolumn{5}{|l|}{ Alleles } \\
\hline G & $57.2(359)$ & $60.6(114)$ & $0.9(0.621-1.208)$ & 0.19 \\
\hline $\mathrm{C}$ & $42.8(269)$ & $39.4(74)$ & $1.1(0.827-1.609)$ & 0.19 \\
\hline $\begin{array}{l}\text { rs1333049 } \\
\text { Genotypes }\end{array}$ & $\begin{array}{l}\text { STEMI } \\
(\mathrm{n}=184)\end{array}$ & $\begin{array}{l}\text { NSTEMI } \\
(\mathrm{n}=128)\end{array}$ & $\begin{array}{c}\text { OR } \\
95 \% \text { CI }\end{array}$ & $P$ \\
\hline GG & $34.2(63)$ & $28.1(36)$ & $1.3(0.814-2.174)$ & 0.12 \\
\hline GC & $50.0(92)$ & $51.6(66)$ & $0.9(0.598-1.475)$ & 0.39 \\
\hline $\mathrm{CC}$ & $15.8(29)$ & $20.3(26)$ & 0.7 (0.408-1.317) & 0.15 \\
\hline \multicolumn{5}{|l|}{ Alleles } \\
\hline G & $59.2(218)$ & $53.9(138)$ & $1.2(0.900-1.714)$ & 0.09 \\
\hline $\mathrm{C}$ & $40.8(150)$ & 46.1 (118) & $0.8(0.583-1.110)$ & 0.09 \\
\hline
\end{tabular}

and without hypertension (HT) was established, considering the dominant inheritance model, observing a significantly increased frequency of the wild-type homozygous GG genotype in patients with HT when compared to non-hypertensive patients. By contrast, a significantly increased frequency of the heterozygous GC genotype was observed in non-hypertensive patients with respect to hypertensive patients, although this significance is lost when correcting the p-value (Table 3 ). On the other hand, the comparison of the genotype frequencies between hypertensive and non-hypertensive patients who suffered AMI, aged $\geq 56$ years, showed a significantly increased frequency of the GG genotype in the group of hypertensive AMI patients. Likewise, the comparison of the frequencies of the genotypes and alleles between hypertensive and non-hypertensive patients who suffered AMI, aged $\leq 55$ years, showed a significantly increased frequency of the GG genotype in the group of hypertensive patients (Table 3). Finally, when establishing the comparison of frequencies between hypertensive AMI patients and hypertensive controls, a significantly increased frequency of the GG genotype was observed in hypertensive AMI patients as compared to hypertensive controls.

These results confirm that the GG genotype confers susceptibility to the development of arterial hypertension, which leads the development of AMI regardless of age.

Another observed correlation is the negative correlation between the rs1333049 polymorphism and the age of occurrence of AMI (r: -0.108, p: 0.042). Based on this correlation, the genotype frequencies between patients who suffered AMI, aged $\leq 55$ years, were compared with the group of patients who suffered AMI, aged $\geq 56$ years, considering the dominant inheritance model and adjusted for CVRF. In the group of patients aged $\geq 56$ years, a significantly increased frequency of the CC genotype was observed with respect to the group of patients who suffered AMI, aged $\leq 55$ years (Table $3)$. These results indicate that individuals with the CC genotype are more likely to suffer AMI at ages $\geq 56$ years.

The severity of CAD was determined in 76 patients with AMI. In this group, more than $50 \%$ of 
Table 3 - Association of rs1333049 polymorphism in the $9 p 21$ locus with hypertension and age of occurrence of AMI

\begin{tabular}{|c|c|c|c|c|c|}
\hline $\begin{array}{l}\text { rs1333049 } \\
\text { Genotypes }\end{array}$ & $\begin{array}{l}\text { AMI patients } \\
\text { HT }(n=202)\end{array}$ & $\begin{array}{c}\text { AMI patients } \\
\text { not } \\
\text { HT }(n=110)\end{array}$ & $\begin{array}{c}\text { OR } \\
95 \% C I\end{array}$ & $p$ & $P c$ \\
\hline GG & $37.6(76)$ & $20.9(23)$ & $2.3(1.328-3.917)$ & 0.0012 & 0.0036 \\
\hline GC & $47.0(95)$ & $57.3(63)$ & 0.7 (0.430-1.046) & 0.042 & 0.126 \\
\hline $\mathrm{CC}$ & $15.3(31)$ & $21.8(24)$ & 0.7 (0.395-1.203) & 0.076 & 0.228 \\
\hline \multicolumn{6}{|l|}{ Alelles } \\
\hline G & $61.1(247)$ & 49.5 (109) & $1.6(1.150-2.231)$ & 0.002 & 0.004 \\
\hline $\mathrm{C}$ & 38.9 (157) & $50.5(111)$ & $0.6(0.448-0.869)$ & 0.002 & 0.004 \\
\hline $\begin{array}{l}\text { rs1333049 } \\
\text { Genotypes }\end{array}$ & $\begin{array}{c}\text { AMI patients } \\
\text { HT Age } \geq 56 \text { years } \\
(n=100)\end{array}$ & $\begin{array}{l}\text { AMI patients not } \\
\text { HT Age } \geq 56 \text { years } \\
(n=42)\end{array}$ & $\begin{array}{c}\text { OR } \\
95 \% C I\end{array}$ & $p$ & $P c$ \\
\hline GG & $34.0(34)$ & $16.7(7)$ & $2.6(1.035-6.403)$ & 0.019 & 0.057 \\
\hline GC & $47.0(47)$ & $52.4(22)$ & $0.8(0.391-1.659)$ & 0.27 & 0.81 \\
\hline $\mathrm{CC}$ & $19.0(19)$ & $30.9(13)$ & $0.5(0.229-1.191)$ & 0.06 & 0.18 \\
\hline \multicolumn{6}{|l|}{ Alelles } \\
\hline G & 57.5 (115) & $42.9(36)$ & $1.8(1.077-3.019)$ & 0.012 & 0.036 \\
\hline $\mathrm{C}$ & $42.5(85)$ & $57.1(48)$ & $0.5(0.331-0.927)$ & 0.012 & 0.036 \\
\hline $\begin{array}{l}\text { rs1333049 } \\
\text { Genotypes }\end{array}$ & $\begin{array}{c}\text { AMI patients } \\
\text { HT Age } \leq 55 \text { years } \\
(n=102)\end{array}$ & $\begin{array}{l}\text { AMI patients not } \\
\text { HT Age } \leq 55 \text { years } \\
(n=68)\end{array}$ & $\begin{array}{c}\text { OR } \\
95 \% \text { CI }\end{array}$ & $p$ & $P c$ \\
\hline GG & $41.2(42)$ & $23.5(16)$ & $2.2(1.146-4.513)$ & 0.008 & 0.024 \\
\hline GC & $47.1(48)$ & $60.3(41)$ & $0.6(0.314-1.090)$ & 0.04 & 0.12 \\
\hline $\mathrm{CC}$ & $11.8(12)$ & $16.2(11)$ & $0.7(0.285-1.670)$ & 0.20 & 0.60 \\
\hline \multicolumn{6}{|l|}{ Alelles } \\
\hline G & $64.7(132)$ & $53.7(73)$ & $1.6(1.016-2.463)$ & 0.02 & 0.04 \\
\hline $\mathrm{C}$ & $35.3(72)$ & $46.3(63)$ & $0.6(0.405-0.984)$ & 0.02 & 0.04 \\
\hline $\begin{array}{l}\text { rs1333049 } \\
\text { Genotypes }\end{array}$ & $\begin{array}{l}\text { AMI patients } \\
\text { Age } \leq 55 \text { years } \\
\quad(n=170)\end{array}$ & $\begin{array}{l}\text { AMI patients } \\
\text { Age } \geq 56 \text { years } \\
\quad(n=142)\end{array}$ & $\begin{array}{c}\text { OR } \\
95 \% \text { CI }\end{array}$ & $p$ & $P c$ \\
\hline GG & $34.1(58)$ & $28.9(41)$ & $0.8(0.484-1.269)$ & 0.16 & 0.32 \\
\hline GC & $52.4(89)$ & $48.6(69)$ & $0.9(0.550-1.343)$ & 0.25 & 0.75 \\
\hline $\mathrm{CC}$ & $13.5(23)$ & $22.5(32)$ & $1.85(1.036-3.354)$ & 0.018 & 0.036 \\
\hline \multicolumn{6}{|l|}{ Alelles } \\
\hline G & $60.3(205)$ & $53.2(151)$ & $0.7(0.543-1.028)$ & 0.03 & 0.09 \\
\hline $\mathrm{C}$ & 39.7 (135) & 46.8 (133) & $1.3(0.972-1.839)$ & 0.03 & 0.09 \\
\hline
\end{tabular}

The genotype and allele frequencies are expressed in percentages, followed by the number of individuals or chromosomes in parentheses. AMI: Acute myocardial infarction, OR: Odds ratio (probability ratio), CI: confidence interval, p: probability value, pc: probability value corrected. 
patients with AMI were clinically classified as patients with STEMI.

In the echocardiographic characteristics of the included patients, the left ventricular systolic function was investigated at the time of admission, estimating a slight decrease $(40.59 \% \pm 9.05)$.

Based on the diagnostic coronary angiography, it was demonstrated that most of the patients had significant obstructive coronary artery disease of the epicardial arteries and only a low percentage had non-significant obstructive coronary artery disease (non-CAD).

CAD severity was defined according to the number of involved coronary arteries. It was observed that more than $60 \%$ of the patients had one main affected coronary vessel, and a low percentage of the patients had three main vessels affected. The most frequently affected artery was the anterior descending artery (ADA), followed by the right coronary artery (RCA), the circumflex artery (CxA), and the left coronary artery (LCA) (Table 4).

Using the SNPstats program, the inheritance model of the homozygous mutated genotype (GG) of the rs10757274 polymorphism in the $9 p 21$ locus was determined, establishing the additive model (2 (GG) + GA vs. AA) as the most adjusted, by presenting the lowest probability value. This pattern of inheritance indicates that the risk conferred by the genotype depends on the number of copies of the mutated allele (allele G). Therefore, individuals with the mutated homozygous GG genotype have twice the risk compared to individuals with the heterozygous AG genotype.

The correlation analysis showed a positive correlation between the rs 10757274 polymorphism with the severity of CAD (number of involved coronary arteries) in patients aged $\leq 55$ years (r: 0.276, p: 0.0078). Based on the correlation and the additive inheritance model, comparison of genotype frequencies was established between patients with an affected coronary vessel and patients with more than one affected vessel, observing a significantly increased frequency of AG + GG genotypes in patients with two or three affected vessels when compared to patients with only one affected vessel. On the contrary, a significantly increased frequency of the AA genotype was observed in patients with only one affected coronary vessel (Table 5).

Considering that the GG genotype of the rs1333049 polymorphism confers susceptibility to the development of arterial hypertension, the frequency of the haplotypes formed by the polymorphisms rs1333049 and rs10757274

\begin{tabular}{|c|c|}
\hline \multicolumn{2}{|c|}{$\begin{array}{l}\text { Table } 4 \text { - Angiographic characteristics of patients with } \\
\text { AMI under } 55 \text { years of age }\end{array}$} \\
\hline Angiographic characteristics & Frequency $(n=76)$ \\
\hline CAD & $96.05(73)$ \\
\hline non-CAD & $3.94(3)$ \\
\hline \multicolumn{2}{|c|}{ Number of involved coronary arteries } \\
\hline One & $63.2(48)$ \\
\hline Two & $32.9(25)$ \\
\hline Three & $3.9(3)$ \\
\hline \multicolumn{2}{|l|}{ Affected artery } \\
\hline ADA & $68.42(52)$ \\
\hline RCA & $40.7(31)$ \\
\hline $\mathrm{CxA}$ & $30.2(23)$ \\
\hline LCA & $6.57(5)$ \\
\hline \multicolumn{2}{|c|}{$\begin{array}{l}\text { Frequencies are expressed in percentages. The values shown in } \\
\text { parentheses represent the number of individuals. CAD: significant } \\
\text { obstructive coronary artery disease, non-CAD: non-significant } \\
\text { obstructive coronary artery disease. ADA: anterior descending artery, } \\
\text { RCA: right coronary artery (RCA), CxA: circumflex artery, LCA: left } \\
\text { coronary artery (LCA). }\end{array}$} \\
\hline
\end{tabular}

was compared between hypertensive and nonhypertensive AMI patients, observing an increased frequency of the haplotype GG, which is formed by the variant $G$ of the rs1333049 polymorphism, associated with hypertension, and the $G$ variant of the rs10757274 polymorphism, associated with severity (greater number of affected vessels) (0.2605 vs. 0.1111 , respectively). By contrast, in non-hypertensive patients a significantly increased frequency of the CG haplotype was observed when compared to hypertensive AMI patients (0.3389 vs. 0.1827 , respectively). Confirming the relevance of the GG genotype of rs1333049 in the development of arterial hypertension.

\section{Discussion}

Cardiovascular diseases represent the main cause of death in many Latin American countries, with rates similar to those of developed countries. Indeed, in the Venezuelan population, diseases of the heart and blood vessels are the main cause of death and represent a growing health, social, and economic burden for the country. Likewise, Venezuela exhibits one of the highest premature mortality rates from myocardial infarction in the region of the 
Table 5 - Association of rs10757274 polymorphism in the 9p21 locus with severity of coronary artery disease

\begin{tabular}{|c|c|c|c|c|c|}
\hline $\begin{array}{l}\text { rs10757274 } \\
\text { Genotypes }\end{array}$ & $\begin{array}{l}\text { AMI patients } \\
\text { Only one } \\
\text { affected vessel } \\
(n=48)\end{array}$ & $\begin{array}{l}\text { AMI patients } \\
2 \text { or more } \\
\text { affected vessels } \\
(n=28)\end{array}$ & $\begin{array}{c}\text { OR } \\
95 \% \text { CI }\end{array}$ & $p$ & $p c$ \\
\hline $\mathrm{GG}+\mathrm{AG}$ & $70.8(34)$ & $89.3(25)$ & $\begin{array}{c}3.8 \\
(0.994-14.401)\end{array}$ & 0.02 & 0.04 \\
\hline AA & $29.2(14)$ & $10.7(3)$ & $\begin{array}{c}0.3 \\
(0.069-1.005)\end{array}$ & 0.02 & 0.04 \\
\hline
\end{tabular}

Americas. ${ }^{2}$ However, during the decade of 2000-2010, the Americas reported a reduction in the premature mortality rate caused by cardiovascular diseases, coinciding with a period of economic development in most Latin American countries, accompanied by a moderate reduction in poverty and greater emphasis on social services. However, the Pan American Health Organization (PAHO) recognizes that access to health services is still unequal, and the distribution of public health expenditures is poor or insufficient, with a high cost for the population. ${ }^{25}$ In Latin American countries, the prevalence of hypertension varies from $8 \%$ to $40 \%$ in the adult population, but an average of $20 \%$ to $23 \%$ of this population has high blood pressure. This prevalence is similar to that of developed countries; however, there is considerable variability in each of the countries and their regions. Therefore, studies of prevalence and local factors in the development of hypertension are reasons for research. ${ }^{26}$ Considering that CAD is a complex and multifactorial cardiovascular disorder caused by the interaction of risk factors, and genetic and environmental factors, and that Venezuela exhibits one of the highest premature mortality rates due to myocardial infarction in the region, the following main findings were observed in the present study:

1. $49.4 \%$ of the patients included in the study suffered AMI at an early age, with an age range between $24-55$ years and an average age of $46.56 \pm 6.53$ years. According to data from PAHO, Venezuela exhibits one of the highest premature mortality rates from myocardial infarction in the region and is one of the most lagging nations in the Americas in meeting global goals to reduce premature mortality due to cardiovascular disease. ${ }^{27}$ However, it has been shown that $80 \%$ of mortality from ischemic heart disease is preventable. Consequently, it is urgent to apply the Global Strategy and Plan of Action of the World Health Organization (WHO) and PAHO to accelerate the implementation of cost-effective measures to slow down and reduce the epidemic of ischemic heart disease in Venezuela. ${ }^{2}$

2. This is the first study of its kind to demonstrate a positive correlation between the rs1333049 polymorphism in the $9 p 21$ locus and arterial hypertension in Venezuelan patients who suffered AMI. In contrast to other studies, where an association with CAD has been established, it was observed that patients with the GG genotype are more likely to develop HT, which makes them more susceptible to suffering myocardial infarction, since the first factor of risk for this pathology is high blood pressure.

3. Patients with the CC genotype of rs1333049 polymorphism in the $9 p 21$ locus are more likely to suffer AMI at older ages ( $\geq 56$ years), which runs in line with what has been previously described in the literature. ${ }^{28}$

4. In patients with AMI, the rs10757274 polymorphism in the $9 p 21$ locus is correlated and associated with the severity of CAD (number of involved coronary arteries). Patients aged $\leq 55$ years and the presence of risk $G$ allele (AG + GG) have a greater possibility $(\sim 4)$ of suffering CAD in a greater number of vessels. In contrast, the AA genotype would be associated with involvement of a single coronary vessel. Previous studies have established the association of polymorphisms in the 9p21 locus with angiographic severity and clinical prognosis of patients with CAD. ${ }^{29}$ 


\section{Considerations and Limitations}

Some limitations in this study must be considered: First, it is an association study of a candidate locus which hinders the explanation of the full heritability of a complex disease. In fact, to explain the heritability, it is important to detect common variants with very small effects, rare variants with small effects, genes harboring ultra-rare variants, and complex interactions (gene - gene and gene - environment). Furthermore, the present study is restricted due to the investigation of two SNPs. A haplotype-based analysis may better disclose the genetic basis of CAD and hypertension in the population of Venezuela. On the other hand, it is a study of a local population; however, the population of Venezuela consists of several ethnic groups (European, African, and Amerindian groups). Thus, the findings in the study could be explained by the ethnic admixture existing in the Venezuelan population, which is highly admixed due to continuous population migrations from other continents and within the continent. Finally, another of the limitations was to determine the severity of CAD in all patients included in the study due to the lack of resources in the hospitals of the country. Therefore, it is important to increase the sample size to confirm the association of rs1333049 with hypertension, to verify the correlation of rs10757274 with severe CAD, as well as to determine the possible relations between the rs10757274 polymorphism and other risk factors for AMI, including the rs1333049 polymorphism associated with hypertension in Venezuelan patients.

\section{Conclusions}

In the studied population, the rs1333049 polymorphism in the 9p21 locus is correlated with arterial hypertension, considered the largest health problem worldwide, and is attributed to approximately 9.4 million deaths per year. Furthermore, HT is the first predisposing factor for the development of AMI, and it is estimated that approximately $30 \%$ of the cases are determined by genetic factors. The rs1333049 polymorphism in the $9 p 21$ locus resides within the neighborhood of cell cycle regulatory genes and is in strong linkage disequilibrium with genes that inhibit the cell cycle, including the inhibitors of cyclin-dependent kinase 2A and 2B (CDKN2A and CDKN2B). Consequently, the dysregulation of these proteins can increase the expression of genes that cause cell proliferation, promoting the development of cell hyperplasia, which would lead to an increase in peripheral vascular resistance, causing arterial hypertension and conferring greater susceptibility to suffer AMI. Finally, this study shows that the rs10757274 polymorphism in the $9 p 21$ locus is associated with the progression of coronary atherosclerosis, suggested by the correlation with the number of involved coronary arteries.

\section{Acknowledgments}

Our gratitude to the patients and staff of the Hospital Central del Instituto Venezolano de los Seguros Sociales "Dr. Miguel Pérez Carreño", and the Servicio de Cardiología, Hospital General del Este "Dr. Domingo Luciani". Caracas, Venezuela.

\section{Potential Conflict of Interest}

No potential conflict of interest relevant to this article was reported.

\section{Sources of Funding}

There were no external funding sources for this study.

\section{Study Association}

This study is not associated with any thesis or dissertation work.

\section{Ethics approval and consent to participate}

This study was approved by the Ethics Committee of the Instituto Venezolano de Investigaciones under the protocol number DIR-0130/09; No. 00211. All the procedures in this study were in accordance with the 1975 Helsinki Declaration, updated in 2013. Informed consent was obtained from all participants included in the study.

\section{Author contributions}

Conception and design of the research: Blanco Sobrino S, Fernández-Mestre M. Acquisition of data: SalazarAlcalá E, Alfonso Reyes A, Flores Soler J, Leras Mirabal R, Luti Y, Márquez I. Analysis and interpretation of the data: Blanco Sobrino S, Salazar-Alcalá E, FernándezMestre M. Statistical analysis: Fernández-Mestre M. Obtaining financing: Fernández-Mestre M. Writing of the manuscript: Blanco Sobrino S, Fernández-Mestre M. Critical revision of the manuscript for intellectual content: Fernández-Mestre M. 


\section{References}

1. World Health Organization (WHO). Global Burden Disease 2017.[Cited in 2020 jan 23] Available from: ghdx.healthdata.org/gbd-2017

2. Núñez Medina T. Myocardial infarction in Venezuela: S.O.S. The impact of the pandemic of ischemic heart disease in Venezuela. Estimates of the burden of cardiovascular disease by 2015. Avances Cardiol. 2016; 36 (4):191-.

3. Çakmak HA, Bayoğlu B, Durmaz E, Can G, Karadağ B, Cengiz M, et al. Evaluation of association between common genetic variants on chromosome 9p21 and coronary artery disease in Turkish population. Anatol J Cardiol. 2015;15:196-203.

4. Roberts R, Stewart AF. 9p21 and the Genetic Revolution for Coronary Artery Disease. Clin Chem. 2012;58(1):1104-112.

5. Samani NJ, Erdmann J, Hall AS, Hengstenberg C, Mangino M, Mayer $B$, et al. Genome wide association analysis of coronary artery disease. N Engl J Med. 2007;3(57):443-53.

6. McPherson R, Pertsemlidis A, Kavaslar N, Stewart A, Roberts R, Cox DR, et al. A common allele on chromosome 9 associated with coronary heart disease. Science. 2007; 316:1488-91.

7. Helgadottir A, Thorleifsson G, Manolescu A, Gretarsdottir S, Blondal $\mathrm{T}$, Jonasdottir A, et al. A common variant on chromosome 9p21 affects the risk of myocardial infarction. Science. 2007;316:1491-3.

8. Schunkert H, Götz A, Braund P, McGinnis R, Tregouet DA, Mangino M, et al. Cardiogenics Consortium. Repeated replication and a prospective meta-analysis of the association between chromosome 9p21.3 and coronary artery disease. Circulation. 2008; 117(13):1675-84.

9. Wellcome Trust Case Control Consortium. 2007. Genome-wide association study of 14,000 cases of seven common diseases and 3,000 shared controls. Nature. 447(7145):661-78.

10. Hiura Y, Fukushima Y, Yuno M, Sawamura H, Kokubo Y, Okamura T, et al. Validation of the association of genetic variants on chromosome $9 \mathrm{p} 21$ and $1 \mathrm{q} 41$ with myocardial infarction in a Japanese population. Circ J. 2008;72:1213-7.

11. Hinohara K, Nakajima T, Takahashi M, Hohda S, Sasaoka T, Nakahara $\mathrm{K}$, et al. Replication of the association between a chromosome 9p21 polymorphism and coronary artery disease in Japanese and Korean populations. J Hum Genet. 2008; 53: 357-59.

12. Shen GQ, Li L, Rao S, Abdullah KG, Ban JM, Lee BS, et al. Four SNPs on chromosome 9p21 in a South Korean population implicate a genetic locus that confers high cross-race risk for development of coronary artery disease. Arterioscler Thromb Vasc Biol. 2008; 28(2):360-5

13. Zhou L, Zhang X, He M, Cheng L, Chen Y, Hu FB, Wu T. Associations between single nucleotide polymorphisms on chromosome 9p21 and risk of coronary heart disease in Chinese Han population. Arterioscler Thromb Vasc Biol. 2008;28(11):2085-9.

14. Gori F, Specchia C, Pietri S, Crociati L, Barlera S, Franciosi M, et al. Common genetic variants on chromosome 9p21 are associated with myocardial infarction and type 2 diabetes in an Italian population. BMC Med Genet. 2010;11:60.
15. AshokKumar M, Emmanuel C, Dhandapany PS, Rani DS, SaiBabu R. Haplotypes on 9p21 Modify the Risk for Coronary Artery Disease Among Indians. DNA Cell Biol. 2011;30(2):105-10.

16. Beckie TM, Beckstead JW, Groer MW. The Association Between Variants on Chromosome 9p21 and Inflammatory Biomarkers in Ethnically Diverse Women with Coronary Heart Disease: A Pilot Study. Biol Res Nurs. 2011;13(3):306-19.

17. Liu R, Song L, Jiang L, Tang X, Xu L, Gao Z, et al. Susceptible gene polymorphism in patients with three-vessel coronary artery disease. BMC Cardiovasc Disord. 2020;20:172.

18. Bunce M. PCR-SSP typing in histocompatibility testing. In: Bidwell $\mathrm{JL}$, Navarrette C. Histocompatibility testing. London:Imperial Collage Press; 2000.p:149-86.

19. Ahmed W,Ali IS, Riaz M, Younas A,Sadeque A, Niazi AK, et al. Association of ANRIL polymorphism (rs1333049: C $>$ G) with myocardial infarction and its pharmacogenomic role in hypercholesterolemia. Gene. 2013;515(2):416-20.

20. Nawaz SK, Noreen A, Rani A, Yousaf M, Arshad M. Association of the rs10757274 SNP with coronary artery disease in a small group of a Pakistani population. Anatol J Cardiol. 2015;15(9):709-15.

21. Weintraub WS, Karlsberg RP, Tcheng JE, Boris JR, Buxton AE<, Dove JT, et al. ACCF/AHA 2011 key data elements and definitions of a base cardiovascular vocabulary for electronic health records: a report of the American College of Cardiology Foundation/AHA Task Force on Clinical Data Standards. J Am Coll Cardiol. 2011; 58(2):202-22.

22. Hong EP, Park JW. Sample size and statistical power calculation in genetic association studies. Genomics \& Informatics 2012;10(2):117-22.

23. Solé X, Guino E, Valls J, Iniesta R, Moreno V. SNPStats: a web tool for the analysis of association studies. Bioinformatics. 2006;22(15):1928-9.

24. Nie N, Hull C, Bent D. IBM Statistical Package for the Social Sciences (SPSS Version 20). Chicago: Computer Software; 2011.

25. Ordunez P, Prieto-Lara E, Pinheiro Gawryszewski V, Hennis AJN, Cooper RS. Premature Mortality from Cardiovascular Disease in the Americas-Will the Goal of a Decline of " $25 \%$ by 2025 " be Met? PLoS ONE. 2015;10(10):e0141685.

26. Hernández-Hernández R, Armas-Padilla MC, Armas-Hernández MJ, Velasco M. Hypertension and cardiovascular health in Venezuela and Latin American countries. J Hum Hypertens. 2000;(Suppl1):S2-S5.

27. Organización Panamericana de la Salud. (OPAS) Proyectos de prevención y control de enfermedades no transmisibles e información y análisis de salud y área de desarrollo sostenible y ambiente: enfermedades no transmisibles en las Américas: indicadores básicos. Washington, DC; 2011.[Cited in 2020 Apr 25] Available from: http:// ais.paho.org/chi/brochures/2011/BI_2011_ESP.pdf

28. Zhou LT, Qin L, Zheng DC, Song ZK, Ye L. Meta-analysis of genetic association of chromosome 9p21 with early-onset coronary artery disease. Gene. 2012;510:185-8.

29. Munir MS, Wang Z, Alahdab F, Steffen MW, Erwin PJ, Kullo IJ, et al. The association of 9p21-3 locus with coronary atherosclerosis: a systematic review and meta-analysis. BMC Med Genet.2014; 15:66. 